Article

\title{
A Community of Practice Approach to Planning Water Sensitive Cities in South Africa
}

\author{
Kirsty Carden ${ }^{1, *}$ and Jessica Fell ${ }^{2}$ \\ ${ }^{1}$ Future Water Research Institute, University of Cape Town, South Africa; E-Mail: kirsty.carden@uct.ac.za \\ 2 Department of Civil Engineering, University of Cape Town, South Africa; E-Mail: flljes003@myuct.ac.za \\ * Corresponding author
}

Submitted: 1 June 2021 | Accepted: 23 July 2021 | Published: 14 October 2021

\begin{abstract}
As South African cities urbanise alongside climate change, resource constraints, and socio-economic challenges, water sensitive (urban) design (WSD) is slowly gaining traction as a framework to address water security goals and entrench resilience. This article reflects on the progression of WSD in South Africa and discusses the broadening of its initial association with stormwater and physical infrastructure to include critical governance and institutional arrangements and social engagements at the core of a water sensitive transition. The approach is being adapted for the socio-economic challenges particular to South Africa, including basic urban water and sanitation service provision, WSD related skills shortages, a lack of spatial planning support for WSD, and the need for enabling policy. Since 2014, a national WSD Community of Practice (CoP) has been a key driver in entrenching and advancing this approach and ensuring that the necessary stakeholders are involved and sufficiently skilled. The WSD CoP is aimed at promoting an integrative approach to planning water sensitive cities, bridging the gaps between theory and practice and blending the social and physical sciences and silo divisions within local municipalities. Three South African examples are presented to illustrate the role of a CoP approach with social learning aspects that support WSD : (1) the "Pathways to water resilient South African cities" interdisciplinary project which shows the institutional (policy) foundation for the integration of WSD into city water planning and management processes; (2) the Sustainable Drainage Systems training programme in the province of Gauteng which demonstrates a skills audit and training initiative as part of an intergovernmental skills development programme with academic partners; and (3) a working group that is being established between the Institute for Landscape Architecture in South Africa and the South African Institution of Civil Engineering which illustrates the challenges and efforts of key professions working together to build WSD capacity.
\end{abstract}

\section{Keywords}

community of practice; South Africa; urban water resilience; water sensitive cities; water sensitive design

\section{Issue}

This article is part of the issue "Towards Green(er) Cities: Contextualizing Green Benefits for Urban Spaces and Contemporary Societies" edited by Juaneé Cilliers (University of Technology Sydney, Australia).

(C) 2021 by the authors; licensee Cogitatio (Lisbon, Portugal). This article is licensed under a Creative Commons Attribution 4.0 International License (CC BY).

\section{Introduction}

As South African cities urbanise alongside climate change, resource constraints, and socio-economic challenges, water sensitive urban design (WSUD) is slowly gaining traction as a framework to address water security goals and entrench resilience (Carden et al., 2016; Fisher-Jeffes et al., 2017). The country's urban areas are a patchwork of highly unequal formal and informal areas that are afforded varying levels of infrastructure and urban water services. Current path dependencies have locked in an approach of "grey" built water infrastructure, and the centralized water provision and planning and management models supporting it. WSUD offers an alternative systems based approach through its supporting principles of resilient, adaptive, and sustainable 
urban water systems (Wong, 2006; Wong et al., 2020); and a water sensitive city (WSC) intentionally plans for equity and liveability through a combination of physical infrastructure, social engagements, and institutional arrangements (Brown et al., 2016)-although this has yet to be comprehensively tested in developing countries around the world. Almost a decade ago, South Africa began engaging with the potential of WSUD to address its urban challenges (Armitage et al., 2014), initially mostly through an emphasis on stormwater-based infrastructural interventions, but this has since broadened to include institutional elements and water sensitive planning (Fourie et al., 2020a). WSUD is increasingly referred to as water sensitive design (WSD) in South Africa to allow for a broader focus on the development of not only urban and peri-urban communities, but also those in rural environments (Carden et al., 2016). Increasing urbanisation in South Africa has led to the proliferation of peri-urban areas which often take the form of informal settlements or slums. For WSD to be applicable and relevant to the South African context, the concept needs to be able to account for informality. The terms WSUD and WSD are therefore used interchangeably in this document.

In South Africa, water resource management is often considered late in the municipal planning process and in isolation from other urban services (such as transport networks, for example). It typically features a professional culture of civil engineering and other technical experts. Emphasis has largely been placed on expanding water services provision to unserviced communities to redress Apartheid-era inequalities at the expense of maintaining infrastructure and neglecting environmental capital (Cilliers \& Rohr, 2019). This has had knock-on impacts for water quality, particularly as water and wastewater systems take strain from unchecked development. The legacy of Apartheid still lives on across cities, with stark inequalities between formal and highly dense informal areas, the latter remaining poorly serviced with infrastructure backlogs. WSD is seen as an enabler that could ensure both the equitable provision of water services and the creation of cities with enhanced ecosystems, liveable urban spaces, and resilient multifunctional water infrastructure.

Given the nature of the country's urban challenges, embracing and operationalizing the principles of WSD requires significant intentional effort. There are large gaps between theory and practice in municipalities and industry, and water sector stakeholders are in general not skilled to engage with the concept. Tensions exist between the need to address basic water and sanitation service provision and provide water related liveability outcomes associated with the visionary state of a WSC. There is still limited-albeit growing-experience with the implementation of multi-functional WSD measures (including Sustainable Drainage Systems [SuDS], for example), which pose new challenges for all decision makers and necessitate the involvement of mul- tiple disciplines and supporting policies (Dominguez et al., 2009; Tjandraatmadja, 2019). A national WSD Community of Practice (COP) has been active since the WSD Framework and Guidelines were published by the South African Water Research Commission (WRC) in 2014 (see www.wsudsa.org). The WSD CoP has been a key driver in entrenching and advancing WSD through various knowledge sharing, capacity development, and stakeholder engagement activities, with a communitybased approach to action-learning as a central element of the CoP. As will be described in further detail later in this article, Wenger (1998) argues that learning is an intrinsically social process and that one of the primary sites where learning occurs is in CoPs. The WSD learning process in different parts of South Africa can be characterised as informal and situated in social interactions, which have slowly facilitated the uptake of aspects of WSD and a growing commitment to a transition to WSCs.

This article reflects on the progression of WSD in South Africa and discusses the broadening of its initial association with stormwater and physical infrastructure to include critical institutional arrangements and planning processes. The role of the WSD CoP and the associated social learning processes are described. Following this, three related cases from South African cities are presented, demonstrating the type of institutional arrangements and social learning processes related to WSD that are occuring in the country.

\section{The Evolution of Water Sensitive Design in South Africa}

\subsection{Water Sensitive Urban Design and Water Sensitive Cities}

WSUD offers an alternative systems-based approach to conventional centralised urban water management and encompasses all aspects of integrated urban water cycle management, including water supply, sewerage, and stormwater. SuDS constitute the stormwater management component of WSUD and consist of a range of technologies and techniques used to drain stormwater/surface water in a manner that is more sustainable than conventional solutions. SuDS are based on the philosophy of replicating as closely as possible the natural, pre-development drainage from a site, and are typically configured as a sequence of stormwater practices that work together to form a management train (Fletcher et al., 2014). The WSUD concept brings sensitivity to water in urban water planning and management and focuses on integrating the urban water cycle into the built and natural environment to enhance sustainability, liveability, and resilience (Wong \& Brown, 2009). A WSC moves beyond the goal of the provision of water services to the creation of cities with enhanced ecosystems and increased biodiversity, liveable urban spaces with amenity and resilient multi-functional water infrastructure, among others (Brown et al., 2016) - with a view to 
protecting the health of receiving waterways, reducing flood risk, and creating public spaces that harvest, clean, and recycle water.

In contrast to WSUD, conventional approaches to urban water management typically rely on large, centralised storage, conveyance and treatment infrastructure, and a single water source. The paradigm is characterized by a professional culture of civil engineering and technical experts, assumptions of stability and predictability, centralised provision of services, highly localised organisation structures, and strong state regulation. There are strong path dependences that lock-in this approach, and which are supported by planning and decision-making structures that often perpetuate conventional infrastructure investments (Truffer et al., 2010; Walker, 2000).

The three pillars of a WSC, i.e., cities as water supply catchments, cities providing ecosystem services, and cities comprising water educated communities, formed the basis for the Principles for a City of the Future as presented in the document blueprint2013-Stormwater Management in a Water Sensitive City (Wong et al., 2013). Following a series of practitioner envisioning workshops in Australia, Binney et al. (2010) adapted the vision to highlight four themes and 12 principles (Figure 1). The vision emphasizes the importance of including communities, members of the public, and water professionals, and the need for their multiple values of water to be expressed. Networks between communities coupled with their active participation in water systems are highlighted for building WSCs. Proactive, strategic, and collaborative spatial planning is a core feature of the vision of the City of the Future. City planning, infrastructure, and service delivery are achieved through a partnership between urban planners, the water sector, and other key sectors. Historically, the water sector has limited influence over the social, economic, and environmental shape and condition of cities, with the provision of water infrastructure and services considered late in the planning process. Given the expanding societal objectives and changing values for water services, urban planning and the water sector need to collaborate more to incorporate these increasingly complex objectives into urban development decisions to create WSCs (Gleick, 2003; Hoekstra et al., 2018).

\subsection{Building a Community of Practice in Water Sensitive Design in South Africa}

The concepts of WSUD and WSCs emerged in Australia in the 1990s and were formalised in the 2000s through the Cooperative Research Centre for Water Sensitive Cities, Australia. Following on from initial work on sustainable stormwater management at some of the larger municipalities around the country, the South African Guidelines for SuDS were published in 2013 by Armitage et al. (2013) and were closely followed by the Framework and Guidelines for WSUD in South Africa (Armitage et al., 2014). Both of these projects were commissioned by the WRC and undertaken by a team of researchers at the University of Cape Town comprising a multidisciplinary team of civil engineers, social anthropologists, environmental scientists, urban planners, political scientists, landscape architects, urban ecologists, and hydrogeologists. The process included significant stakeholder engagement through workshops and interviews with municipal officials from the Roads and Stormwater, and Water and Sanitation Departments of

PRINCIPLES

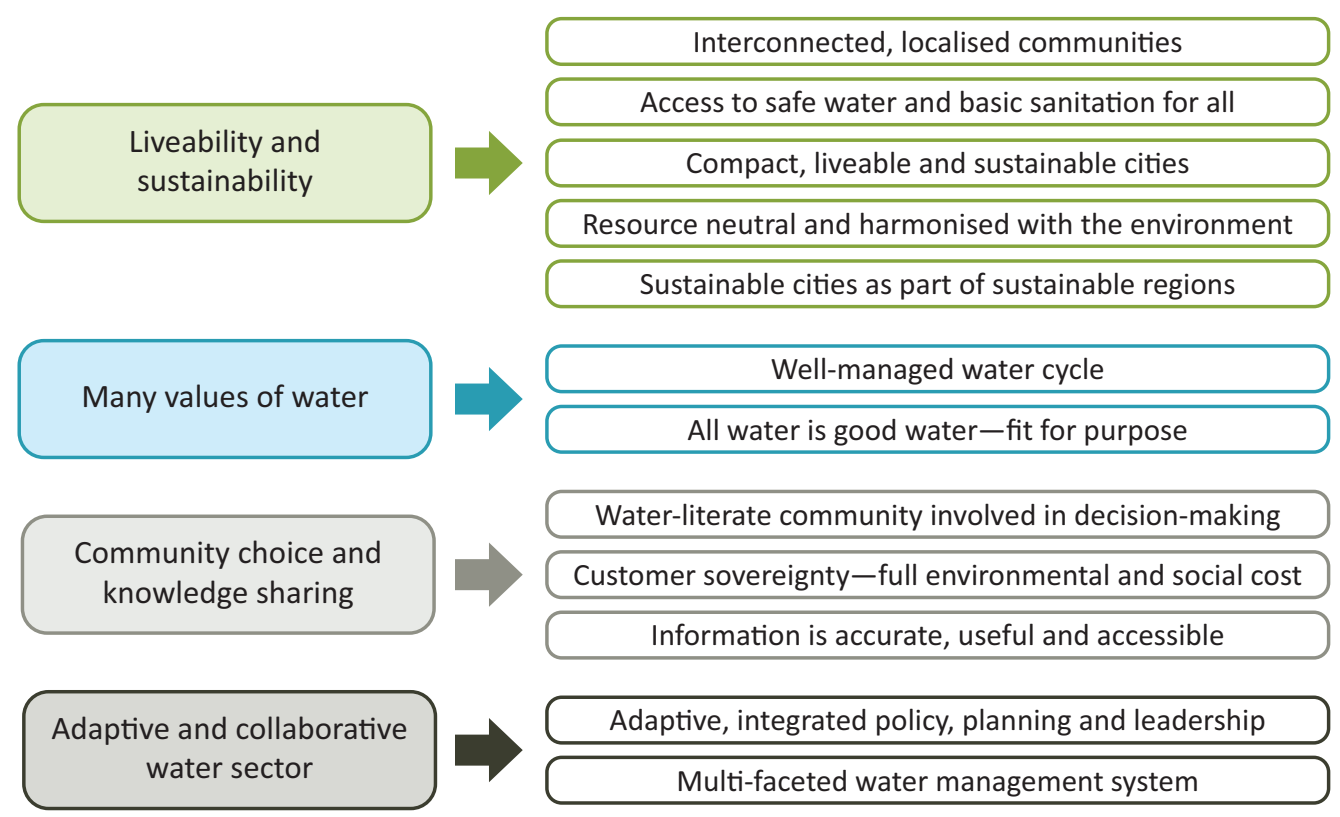

Figure 1. Principles for a City of the Future. Source: Wong et al. (2013, p. 8). 
four of the major metropolitan municipalities-Cape Town, eThekwini, Johannesburg, and Tshwane, as well as Drakenstein, a smaller local authority near Cape Town (Fisher-Jeffes et al., 2017). Environmental planners and stormwater engineers were particularly influential in this process, with their inputs driving the significant focus on stormwater and infrastructure-based interventions. It was at this time that the decision was made to expand the term WSUD for the South African (i.e., developing country) context so as to include a broader focus on periurban and rural areas also; thus, WSD became the preferred terminology.

Early in the guidelines' development process, the concept of "learning alliances" was recognised as an important mechanism to drive WSD uptake and implementation. Butterworth et al. (2011, p. 3) define learning alliances as "platforms that bring together stakeholders from a range of institutions... to think, act and learn together, using action research to test ideas." Networks and relationships, both informal and formal, between and within the project team and stakeholders from the various workshops, provided lessons and a foundation for proposing WSD as a new approach to water management in the country. This insight then led to the establishment of Phase 1 of the WRC-supported WSD CoP programme which ran from 2014 to 2019, and played a key role in awareness-raising and knowledge integration in the field of WSD in South Africa (Carden et al., 2016). As will be described in more detail later in this article, the WSD CoP is currently in the final year of the Phase 2 programme (2019 to 2021) with a strong focus on strengthening its profile and impact narrative towards more widescale implementation of WSD.

The most widely-cited definition of a CoP is "... groups of people who share a concern or passion for something they do and learn how to do it better as they interact regularly" (Wenger, 1998, p. 1). The necessary components of a CoP include a domain (area of shared interest), a community (sense of belonging among members), and a practice (action-learning through participation and reification). A CoP can also be viewed as a communitybased social learning approach to action-learning that aligns with the tradition of systems thinking (Blackmore, 2010). In other words, a CoP is not simply a group or groups of people but rather a social process of negotiating competence in a domain over time. Social learning processes offer potential to build capacity to achieve joint solutions and to make stakeholder participation effective-both critical elements for effective water governance in the context of increasing uncertainty and complexity such as that brought about by climate change and rapid urbanisation. In this regard, Pahl-Wostl et al. (2013) provide compelling arguments for a shift in emphasis from information generated from scientific research that merely informs policy and expert cycles, to strategic partnership approaches that consider multi-perspective and multi-scale knowledge in the pursuit of sustainable water futures. Thus, the social learning embedded within a CoP structure offers a useful framework with tools and methods to analyse and structure the pursuit of WSD at all levels of society, be it at neighbourhood, catchment, city, or country scale.

Given that water resources, as well as WSUD initiatives, can be seen as "common pool" resources, a CoP approach to transitioning to WSCs is of broad value (Leonard et al., 2019). CoPs have played important roles in various countries in adopting sustainable and water sensitive approaches. For example, Gonzalez et al. (2011) detail the role of engaging researchers and practitioners through a COP in developing urban sustainability indicators for five European cities, with the CoP bridging the gap between science and practice and facilitating the selection of meaningful indicators. Allen (2012) advocates for the role of a green infrastructure CoP in the United States and the use of their website to highlight best practice planning and implementation examples across scales and jurisdictional boundaries as well as to convene conferences to facilitate engagement and social learning.

\subsection{Water Sensitive Urban Management and Water Sensitive Urban Planning}

The 2014 Framework and Guidelines for WSUD in South Africa split the WSD term into three components to be considered in an integrated manner, including: i) WSUD brings the concepts of "water sensitivity" and "urban design" together to ensure that "urban design" is undertaken in a water sensitive manner; ii) water sensitive urban planning (WSUP) deals with urban planning and governance aspects to ensure that this is undertaken in a manner that considers and treats water sensitively; and iii) water sensitive urban management (WSUM) deals with the post construction management of water sensitive infrastructure (Armitage et al., 2014).

The first few years after the 2014 framework was published were largely focused on WSUM, as both local government and industry-based professionals (mainly engineers and scientists) grappled with embracing and operationalizing the concept in their respective contexts. In order to implement WSD interventions at that time, emphasis was placed on ensuring technical performance of related infrastructure and establishing the benefit costs and maintenance requirements of these interventions compared to conventional "grey" infrastructure. The early stages of WSD in South Africa were also principally focused on stormwater management. WSUM continues to be a focus in South Africa, with increasing WSUD infrastructure projects. These projects range from the implementation of green infrastructure (often SuDS), which tend to be located within private developments (Shackleton et al., 2018), to hybridised "grey-green" infrastructure. Retrofitting green infrastructure options alongside existing grey infrastructure is increasingly being trialled as an approach towards WSD implementation in South Africa, where limited resources-both 
human and financial-most often need to be utilised for basic service provision. For example, the City of Cape Town has committed to a Liveable Urban Waterways programme through its recent Resilience Strategy (City of Cape Town, 2019a). The programme seeks to rehabilitate urban waterways (largely concrete channels) using WSD principles and through the use of retrofitted green infrastructure. The 2014 WSD framework also advocates for retrofitting infrastructure, especially stormwater infrastructure, for amenity and water quality improvement purposes (Armitage et al., 2014).

For the true expression of WSD, and for the concept to have maximum impact, planning needs to play a crucial role so that WSD principles are strategically included from the start, and at all spatial scales from the metropolitan to the site level (Fourie et al., 2020b). South African cities present complex water planning challenges as a consequence of the fierce competition for land and housing and the dynamic patchworks of formal, informal, and backyarder (i.e., "... secondary dwellings in low-income areas... considered additional structures to the main house and may range between different levels of formality and informality" [Isandla Institute, 2020, p. 4]) housing developments that require different levels of water services. Water departments and spatial planning departments typically lack integration, complicating the realisation of WSCs which depend on strategic urban design and planning (Cilliers \& Rohr, 2019). Moreover, the principles of WSD and WSCs are largely foreign in spatial planning departments in South Africa, with professionals lacking the understanding and competencies needed to spatially integrate WSD into the urban form. Following on from the SuDS and WSD Guideline documents therefore, the publication of the WRC-supported Guidelines on Compiling Water-Sensitive Spatial Plans and Framework Towards Water-Sensitive Spatial Planning and Land Use Management (Fourie et al., 2020a, 2020b) have gone some way to addressing these issues, offering an important starting point for increasing the prominence of urban planning and design in realising WSCs (Figure 2). These two documents provide guidance on spatially translating WSD at the municipal (city) scale within the bounds of South Africa's complex planning legislation. The documents detail various legislative elements pertaining to water resources that exist at national, provincial, sub-catchment, municipal, and area levels that involve multiple stakeholders. However, there is still a long way to go in terms of the development of appropriate tools, stakeholder partnerships, and regulatory and policy structures within local governments to enable the level of integration of planning and water management required to effect a transition to water sensitivity. As water sensitive spatial planning is still in its infancy in South Africa, there are few examples and case studies in the country that the WSD CoP can use to facilitate learning.

\section{Social Learning Associated With the Water Sensitive Design Community of Practice}

The initial phase of the WSD CoP programme (2014 to 2018) included purposeful engagement with a wide group of stakeholders and promoted knowledge integration in the field of WSD through, inter alia, an expanded training programme with a combined reach of over 1,000 water stakeholders in both the public and private sphere in South Africa (Carden, 2019). It was able to indicate that this approach has the potential to generate new understandings about innovative practices and reflexive learning within WSD in South Africa, and to develop knowledge connected to policy development and change to influence planning and design towards WSCs. The main focus areas of the first phase of the WSD CoP programme were:
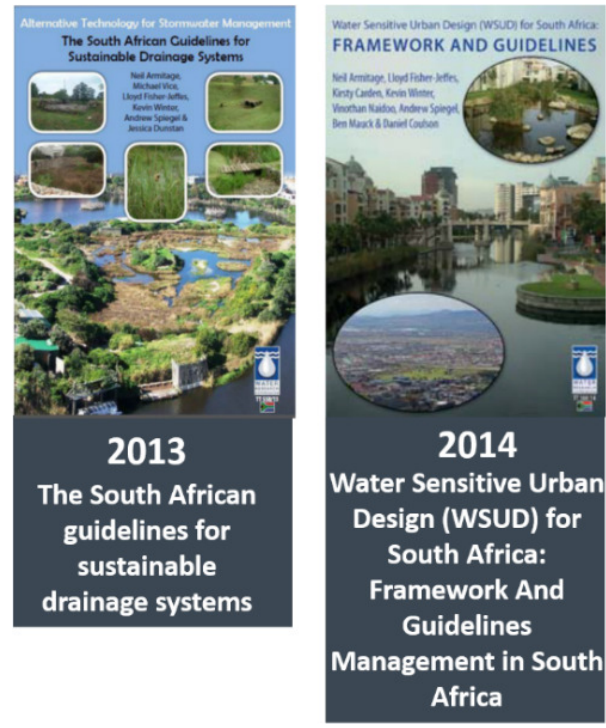
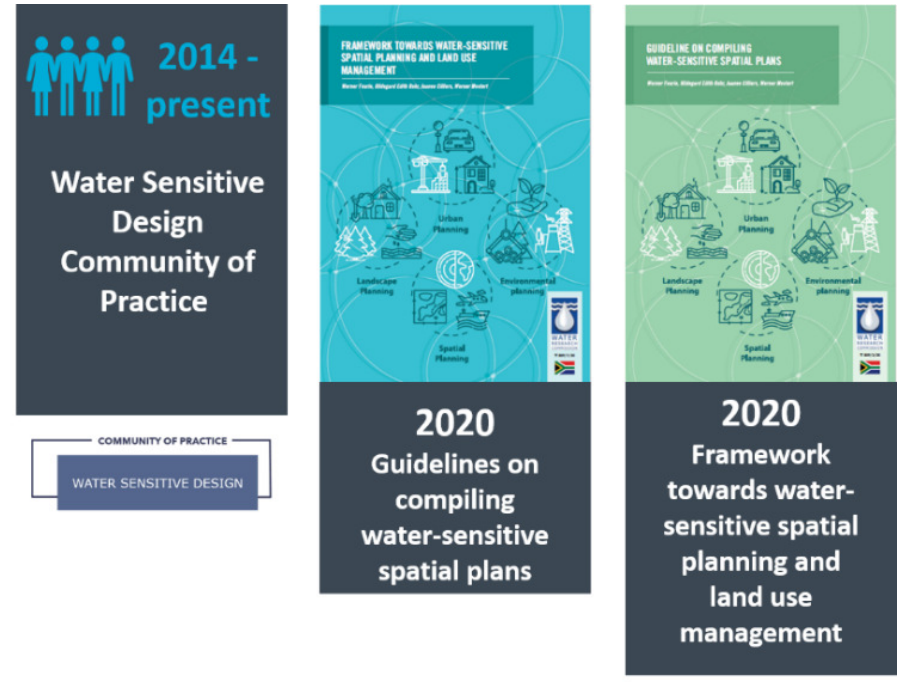

Figure 2. Milestones in the evolution of WSD in South Africa through the publication of guidelines and the establishment of the WSD CoP programme. Source: Authors, based on Armitage et al. $(2013,2014)$ and Fourie et al. $(2020 \mathrm{a}, 2020 \mathrm{~b})$. 
- The identification of possibilities for collaborative and participatory interaction between all relevant actors, including awareness-raising and appropriate WSD training activities-including those hosted collaboratively with partners such as the Centre for Science and Environment (CSE) in India. The training partnership with CSE was established in 2017 with the specific aim of broadening the impact of the WSD capacity-building component of the CoP; in particular, by introducing practical elements on rainwater harvesting and decentralised wastewater treatment from a developing country perspective. CSE India is a public interest research and advocacy organisation based in New Delhi, set up to act as a Centre of Excellence in the area of sustainable urban water management. The collaboration with them enables the sharing of solutions with other countries in the developing world (including other African countries) that engage in common struggles around meeting the water and wastewater treatment needs of urban and rural populations which are affordable and sustainable;

- The establishment of smaller CoPs or learning alliances in different geographic locations with the objective of linking the various actors in these urban water systems and promoting shared learning and innovation around sustainable water management practices. These platforms allowed researchers, local stakeholders, and users to work together to create shared visions, analyse options, and develop new strategies for the management of diverse forms of urban water infrastructure systems;

- Documenting case studies to consider and develop/modify social learning frameworks for adopting WSD mechanisms in the South African context-including the various ongoing and potential projects around the feasibility of WSD strategies, as well other relevant WRC projects related to WSD, e.g., WRC Project K5/2587 "Securing Water Sustainability Through Innovative Spatial Planning and Land Use Management Tools-Case Study of Two Municipalities," that produced the guidelines for developing water sensitive spatial development frameworks and water sensitive land use schemes (Fourie et al., 2020a, 2020b).

The Phase $1 \mathrm{CoP}$ also highlighted some gaps and/or shortcomings however, specifically in terms of the necessity for more targeted training on WSD and planning, broader engagement with a wider group of stakeholders, and for an expansion of the CoP (and strengthening of its profile and impact narrative) in areas other than large metropolitan cities. A second phase of the programme was thus established to run from 2019 to 2021, with the overall aim of facilitating a more widespread uptake of WSD in South Africa.
Some examples of the different types of social learning that have been enabled as part of the South African WSD CoP are provided in the sections that follow, which also attempt to highlight the need for integrative approaches in the planning for WSCs. All of the case studies discussed are ongoing (current in 2021) projects that are beginning to show what is required in order to plan for and transition towards WSCs.

\section{Local WSD CoPs and Case Studies}

This section describes three South African examples that demonstrate the value of a CoP approach with social learning processes.

\subsection{Pathways to Water Resilient South African Cities Project}

Academics at the interdisciplinary Future Water Research Institute at the University of Cape Town and the University of Copenhagen, Denmark, have partnered on a research project entitled "Pathways to Water Resilient South African Cities" (PaWS). The current project aims to identify opportunities for, and generate knowledge on, the physical and institutional integration of decentralised nature-based solutions into the urban water cycle to support and accelerate a transition towards water resilience in South African cities, specifically focusing on the cities of Cape Town and Johannesburg. The project is split into physical and institutional work packages, with the former including physical experimentation and evaluation of WSD options at different urban scales, particularly focusing on repurposing urban stormwater ponds for the treatment and harvesting of surface runoff through managed aquifer recharge and recovery. The latter explores the required governance processes and institutional arrangements for enabling WSD emergent transitions.

The main novelty and contribution of the project lies in the dual consideration of the physical and institutional pathways to water resilience, which historically have been considered separately in WSD-focused South African research. WSD-directed South African research either focuses on infrastructure selection, construction, and evaluation, or the governance and institutional arrangements, and infrequently the planning practices supporting WSD. The interdisciplinary project team therefore intentionally designed the project to explore the links, feedback loops, and supportive structures between infrastructure measures and institutional and planning environments and processes. From the outset, a co-design approach was adopted in both the design of the physical experiments as well as the evaluation of institutional pathways, with a strong focus on social learning processes with identified stakeholders to allow for WSD thinking to be embedded effectively.

The project focus was driven in part by the City of Cape Town's increasing engagement and policy alignment with WSD that spans back to 2009, as well as the 
recent drought and associated "Day Zero" crisis that was largely as a result of significantly below average rainfall during the period 2015 to 2017 (Otto et al., 2018; Wolski et al., 2020). Cape Town relies on conventional centralised water management and planning approaches, with a water supply highly dependent (95\%) on six large rainfed dams located outside of the city boundaries. The water crisis thus became a primary driver of a focused move towards water sensitivity, an acute shock that drove the need for a consolidated water sensitive vision for Cape Town. This was articulated through the document Cape Town Water Strategy-Our Shared Water Future, published in 2019 (City of Cape Town, 2019b). However, WSD had slowly been gaining traction even prior to this drought. As part of the PaWS project, an analysis of the evolution of WSD related planning policy in Cape Town up until 2019 was conducted to highlight the development of institutional pathways towards water resilience (see Figure 3 and the description below). Fifteen policies dating back to 2009 were analysed for the inclusion of WSD principles and for advocating the approach across various organisations and departments.

Prior to the development of the national WSUD Framework and Guidelines in 2014, the City of Cape Town's Catchment, Stormwater and River Management Branch pioneered the adoption of a WSD-centred approach to stormwater management. Two policies were published in 2009-the Floodplain and River Corridor Management Policy and the Management of Urban Stormwater Impacts Policy-both of which required developers to adopt a WSUD approach and were key in driving the uptake of sustainable drainage technologies in particular (such as permeable pavements). In 2013, the Urban Design Policy also advocated for WSUD principles, again framed from a drainage-related perspective; however, there was also acknowledgement of the multi-functional aspects of WSD. This policy was developed with a range of City departments such as Transport (including stormwater management), Water and Sanitation, City Parks, and the Planning and Building Development Management Department. The inclusion of these principles in the policy marked a milestone for WSD in Cape Town, as it heralded the beginning of inter-departmental collaboration in the formulation and uptake of WSD-related policy. In 2017, WSUD was included in three major documents: the City of Cape Town Climate Change Policy; Water Services Development Plan-Integrated Development Plan Water Sector Input Report (2017/18-2021/22) and the Municipal Spatial Development Framework (2017-2022). The Water Services Development PlanIntegrated Development Plan Water Sector Input Report

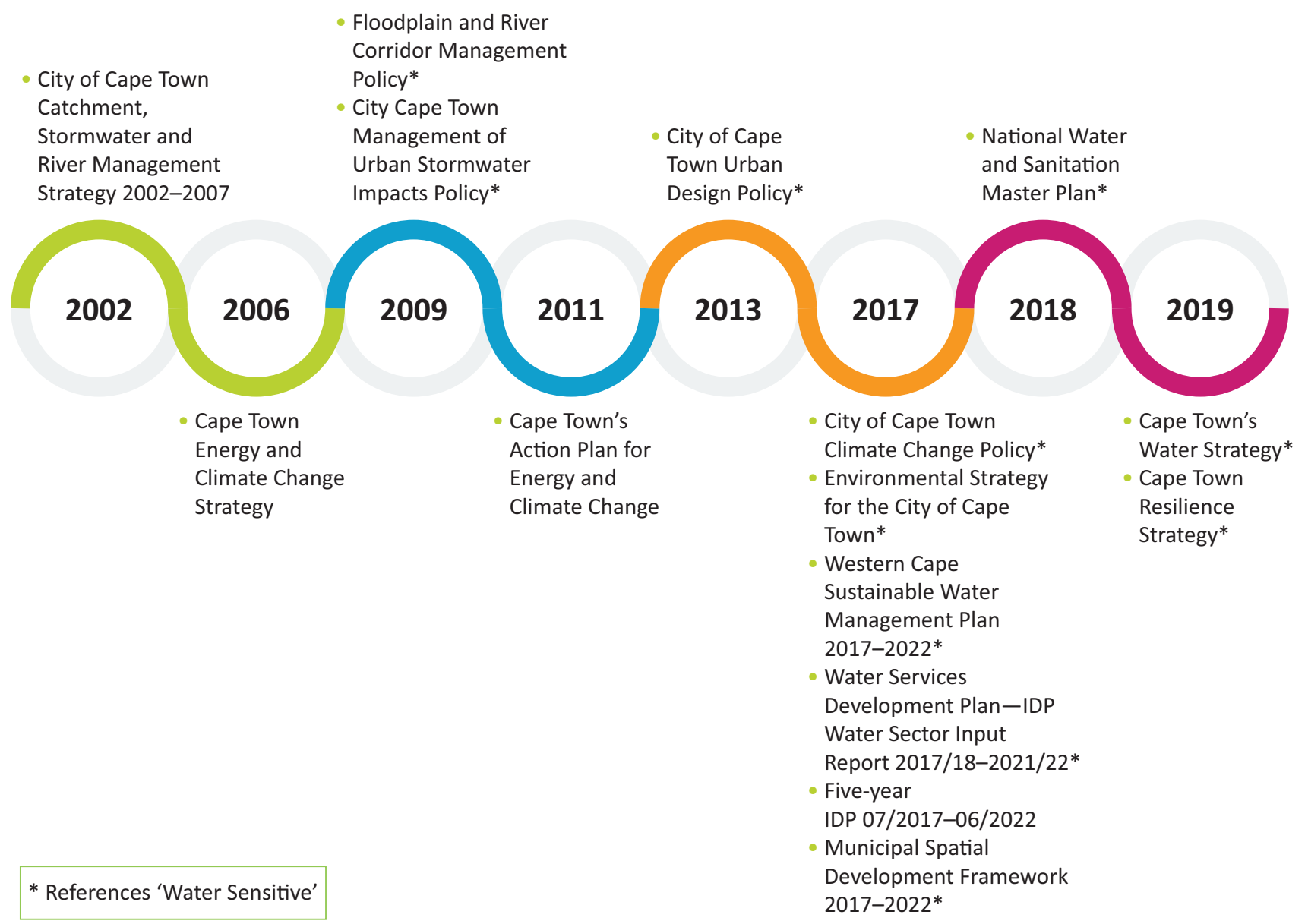

Figure 3. Timeline of selected water policy in Cape Town illustrating the emergence and evolution of WSD/WSC principles. 
articulated a vision "to be a beacon in Africa through the progressive realisation of Cape Town as a water sensitive city" (City of Cape Town, 2017, p. 14). Climate change was cited as a major reason for the paradigm shift to water sensitivity, and the plan was mostly resource and infrastructure management and service delivery oriented. The City of Cape Town has continued with this policy alignment to WSD principles, releasing the Water Strategy with its commitment to becoming a WSC by 2040, as well as the Resilience Strategy (City of Cape Town, 2019a) which also addresses the linkages between water security and other potential shocks (e.g., storm surge and flooding) whilst acknowledging the underlying chronic stresses that weaken the City's ability to respond, such as informality, unemployment, and climate change.

These targeted policy interventions provide the institutional foundation for the integration of WSD into city water planning and management processes and have gone some way to supporting the physical manifestation of multi-functional infrastructure, particularly in respect of SuDS. The evolution of WSD/WSC in the policies from various departments highlights different disciplinary perspectives and illustrates the need for many professions to contribute to WSD. The institutional foundation these policies provide for WSD highlights the skillsets and knowledge required for implementing WSD.

Nonetheless, progress in the City of Cape Town's emergent transition towards water sensitivity continues to be slow-mainly as a result of a dearth of city-specific business cases to support a more coherent adoption of WSD, and a lack of coordination of roles and responsibilities (Mguni \& Carden, 2020). The PaWS project has highlighted the need to build evidence for contextual resilience-building initiatives through engaging in physical and governance experimentation in cities to provide a space for the reconfiguration of capacities, resources, and agency of institutional, business, and civil actors in support of transformative change. Through mapping the various WSD options as well as the identification of participants for the multi-actor transition arena processes (i.e., structured engagements such as workshops and focus group discussions that are aimed at enabling a common understanding amongst stakeholders of the transition challenge faced by cities in the uptake and implementation of a WSD approach), the project has started to address the governance and policy implications of hybridising conventional water infrastructure with green infrastructure in a WSD approach.

\subsection{Gauteng Department of Rural and Agricultural Development SuDS Training Programme}

WSD has also been gaining traction in other provinces around South Africa, specifically in terms of the stormwater management component; for example, the Gauteng Sustainable Drainage Systems (SuDS) Implementation Manual (Gauteng Provincial Government, 2020) was recently published, which strongly promotes the prin- ciples of WSD. In an attempt to ensure the wide-scale uptake of the concepts within the Province, the Gauteng Department of Agriculture and Rural Development (the department responsible for the development of the Manual) has undertaken to support a targeted SuDS capacity development and training initiative as part of an intergovernmental skills development programme. This programme is being coordinated through the University of Johannesburg's Process, Energy and Environmental Technology Station who facilitate the collaboration with the Gauteng Department of Agriculture and Rural Development and define future work aligned with the creation of a dedicated CoP within a triple helix network (i.e., structured interactions between academia, industry, and government that are aimed at fostering economic and social development) around SuDS uptake in Gauteng. The overall intention is to create a group of stakeholders skilled in WSD and SuDS who can start to forge relationships with industry partners and research institutions in the ongoing implementation of SuDS projects.

In recognition of their expertise in the field of SuDS - together with the role they have played in leading the WSD CoP on behalf of the WRC and facilitating the WSD/SuDS training programmes associated with that programme-the Future Water Research Institute have been tasked with the skills audit and training components within the University of Johannesburg's Process, Energy and Environmental Technology Station and Gauteng Department of Agriculture and Rural Development collaboration. The following activities are defined within the context of the existing WSD CoP framework to facilitate knowledge sharing, capacity development and social learning:

- Introductory workshop on SuDS that focuses on encouraging intergovernmental collaboration and establishing the basis for future work, including an overview of the process that led to the development of the Gauteng SuDS Implementation Manual;

- Facilitated SuDS skills audit and gap analysis within Gauteng Province-key stakeholders identified and brought into a carefully-crafted engagement process (including the use of interviews, surveys, and questionnaires) to determine the skills requirements related to the broader-scale implementation of SuDS across government departments in the Gauteng Province, aligned with the Implementation Manual;

- Development of customised SuDS training material for identified priority stakeholder groups and delivery of said training sessions;

- Ongoing SuDS stakeholder mapping in Gauteng Province with the goal of supporting the establishment of a targeted group of stakeholders in multidisciplinary working environments across government departments (local, provincial, and 
national), academia, industry, small, medium, and micro enterprises, non-governmental organisations, and consultants.

Initial findings from this project have revealed that whilst environmental professionals are relatively wellrepresented in the provincial government's structures, there are many knowledge gaps in respect of SuDS implementation. Of more concern is the fact that planning, urban design, landscape architecture (LA), and policy professionals are not yet represented in discussions on the SuDS Implementation Manual, thus highlighting the strong need for awareness-raising and skills development activities in these areas.

\subsection{Institute for Landscape Architecture in South Africa/South African Institution of Civil Engineering WSD Working Group}

There has been growing recognition of the varied skills across built environment disciplines in South Africa (including engineers and landscape architects) where specialists in both of these areas have a range of technical abilities to implement WSD/SuDS-but often have limited understanding of the impact of their individual contributions to the broader WSD development process. As one Cape Town-based landscape architect put it, "Landscape architects are often seen by engineers as green decorators, yet we need the engineers to give practical depth to the LA's sometimes shallow understanding of the problems and safety requirements of their designs." Similarly, engineers acknowledge the critical contribution that LAs make towards building momentum in the uptake and implementation of WSD/SuDS options.

Following a series of green infrastructure webinars held by the Institute for Landscape Architecture in South Africa in late 2020 where engineering professionals were also represented, the decision was taken to try and establish a working group together with the Future Water Research Institute, that would link the two most represented professional bodies in the WSD field; i.e., Institute for Landscape Architecture in South Africa and the South African Institution of Civil Engineering. A small group was assembled representing academia, consultants, and government officials to work towards developing an action plan for enhanced collaboration across these professions, and to build technical support, training, and communication skills development for practitioners in both fields. A specific focus of the working group is to investigate opportunities for collaboration on, and documentation of, integrated green infrastructure and public space projects - with a view to building a local (African) evidence-based repository of peer reviewed case studies to use in promoting WSD/SuDS and climate conscious design of public space to professional colleagues, authorities, and developers. Through the working group sessions, a number of key priorities have been identified to develop momentum towards achieving these outcomes.
These include: the development of short, continuing professional development courses with content structured for interdisciplinary access; co-authoring journal and conference papers; visits to demonstration sites led by design, construction, and maintenance teams; and communication through popular media platforms to address the inconsistencies in understandings of WSD/SuDS and to educate practitioners and members of the public of the value of such an approach.

\subsection{Discussion of Examples}

The three examples provided here represent simple CoPs in their own right, with characteristics of social learning systems (Blackmore, 2010) and the necessary components of a CoP, i.e., a domain (area of shared interest), a community (sense of belonging among members), and a practice (action-learning through participation and reification). The examples illustrate the importance of uunderstanding how key professions work together and where the gaps in knowledge are to ensure the necessary integration at an institutional level to support widespread implementation of WSD. In the first example, the "Pathways to Water Resilient South African Cities" project highlighted the role of an institutional foundation, with a history of supporting policy, for the integration of WSD into city water planning and management processes. The diversity of departments and disciplines reflected in the policies illustrate the multiple key professions involved in WSD. The project also highlighted the need to build evidence bases for both WSD physical and governance intervention which provide knowledge for the reconfiguration of capacities, resources, and agency of institutional, business, and civil actors. The SuDS training programme in the second example discussed a partnership between academia and governmental bodies to facilitate knowledge sharing, capacity development, and social learning. Once again, developing means to bring key professions together and ensure a broader representation of disciplines for WSD implementation was highlighted. The WSD working group with the Institute for Landscape Architecture in South Africa and the South African Institution of Civil Engineering similarly used a CoP approach with social learning to link key WSD professionals. Enhancing collaboration across these professions, and building technical support, training, and communication skills development for practitioners in both fields were key priorities.

\section{Conclusions}

The development of the South African WSD Framework and Guidelines, the Water Sensitive Spatial Planning Framework and Guidelines, along with the initial associated learning alliance/s and subsequent WSD CoP that was established, reflect the importance of both physical and institutional elements in transitioning to water sensitivity in urban areas. Simply publishing guidelines 
on WSD to enable the implementation of physical infrastructure-based interventions is not enough; this needs to be accompanied by the establishment of communities of water professionals, the support of social learning, transferring of knowledge to influential water sector stakeholders, and ensuring enabling policy environments. Three examples have been presented in this article that highlight the role and value of CoPs in bringing key professions together to learn from one another's perspectives and ensure that the necessary WSD skills and competencies exist across the country, as well as building momentum for and supporting the necessary planning processes to effect change.

From a social learning perspective, the intended outcome of CoPs is to grow "communities of communities" or "landscapes of practice" where local-level learning experiments benefit from and contribute to an overall learning system pertaining to the required transition for embedding a new paradigm such as WSD at city scale. The key insights of such a fractal structure are that the concepts of WSD become sufficiently embedded in the institutional pathways and processes related to the planning of WSCs in South Africa and beyond.

\section{Acknowledgments}

Research funding provided by the Water Research Commission of South Africa (Project K5/2413) as well as the Danish Fellowship Centre (Project 18-MO5-KU) is gratefully acknowledged.

\section{Conflict of Interests}

The authors declare no conflict of interests.

\section{References}

Allen, W., III. (2012). Advancing green infrastructure at all scales: From landscape to site. Environmental Practice, 14(1), 17-25. https://doi.org/10.1017/ S1466046611000469

Armitage, N., Fisher-Jeffes, L., Carden, K., Winter, K., Naidoo, V., Spiegel, A., Mauck, B., \& Coulson, D. (2014). Water sensitive urban design (WSUD) for South Africa: Framework and guidelines (Report No. TT 588/14). Water Research Commission. http:// wrcwebsite.azurewebsites.net/wp-content/ uploads/mdocs/TT\%20588-13.pdf

Armitage, N., Vice, M., Fisher-Jeffes, L., Winter, K., Spiegel, A., \& Dunstan, J. (2013). Alternative technology for stormwater management: The South African guidelines for sustainable drainage systems (Report No. TT558/13). Water Research Commission. http:// www.wrc.org.za/wp-content/uploads/mdocs/ TT\%20558.pdf

Binney, P., Donald, A., Elmer, V., Ewert, J., Phillis, O., Skinner, R., \& Young, R. (2010). Spatial planning and institutional reform conclusions from the World Water
Congress, September 2010. IWA Cities of the Future Program. https://www.clearwatervic.com.au/userdata/resource-files/Conclusions-Cities-of-theFuture-Montreal_2011.pdf

Blackmore, C. (2010). Social learning systems and communities of practice. Springer.

Brown, R., Rogers, B., \& Werbeloff, L. (2016). Moving toward water sensitive cities: A guidance manual for strategists and policy makers. Cooperative Research Centre for Water Sensitive Cities. https:// watersensitivecities.org.au/wp-content/uploads/ 2016/05/TMR_A4-1_MovingTowardWSC.pdf

Butterworth, J., Mclntyre, P., \& da Silva Wells, C. (2011). SWITCH in the city: Putting urban water management to the test. IRC. https://www.ircwash.org/sites/ default/files/Butterworth-2011-SWITCH_1.pdf

Carden, K. (2019). WRC research project K5/2413Development and management of a water sensitive design community of practice programme (D11: Final report Phase 1). Unpublished manuscript.

Carden, K., Ellis, D., \& Armitage, N. (2016). Water sensitive cities in South Africa: Developing a community of practice. WIT Transactions on the Built Environment, 165, 51-62. https://doi.org/10.2495/UW160051

Cilliers, E., \& Rohr, H. (2019). Integrating WSUD and mainstream spatial planning approaches: Lessons from South Africa. In D. Sharma, A. Gardner, \& T. Begbie (Eds.), Approaches to water sensitive urban design: Potential, design, ecological health, urban greening, economics, policies, and community perceptions (pp. 351-366). Woodhead Publishing.

City of Cape Town. (2017). Water Services Development Plan - IDP Water Sector input report (No. FY 2017/ 18-2021/22).

City of Cape Town. (2019a). Cape Town resilience strategy.

City of Cape Town. (2019b). Our shared water future: Cape Town's water strategy.

Dominguez, D., Worch, H., Markard, J., Truffer, B., \& Gujer, W. (2009). Closing the capability gap: Strategic planning for the infrastructure sector. California Management Review, 51(2), 30-50.

Fisher-Jeffes, L., Carden, K., \& Armitage, N. (2017). A water sensitive urban design framework for South Africa. Journal of Town \& Regional Planning, 2017(71), 1-10. https://doi.org/10.18820/24150495/trp71i1.1

Fletcher, T., Shuster, W., Hunt, W., Ashley, R., Butler, D., Arthur, S., Trowsdale, S., Barraud, S., SemadeniDavies, A., Bertrand-Krajewski, J.-L., Mikkelsen, P., Rivard, G., Uhl, M., Dagenais, D., \& Viklander, M. (2014). SUDS, LID, BMPs, WSUD and moreThe evolution and application of terminology surrounding urban drainage. Urban Water Journal, 12(7), 525-542. https://doi.org/10.1080/1573062X. 2014.916314

Fourie, W., Rohr, H., Cilliers, J., \& Mostert, W. (2020a). Guideline on compiling water-sensitive spatial 
plans (Report No. TT 809/2/19). Water Research Commission. http://wrcwebsite.azurewebsites.net/ wp-content/uploads/mdocs/TT809-2-19\%20final\% 20web.pdf

Fourie, W., Rohr, H., Cilliers, J., \& Mostert, W. (2020b). Framework towards water-sensitive spatial planning and land use management (Report No. TT 809/1/19). Water Research Commission. http://wrcwebsite. azurewebsites.net/wp-content/uploads/mdocs/ TT809-1-19\%20final\%20web.pdf

Gauteng Provincial Government. (2020). Gauteng sustainable drainage systems implementantion manual. http://www.futurewater.uct.ac.za/sites/default/ files/image_tool/images/416/Future_Water/ Documents/Gauteng\%20PG\%20\%282020\%29\% 20Del\%208\%20Implementation\%20Manual_SuDS\% 20in\%20Gauteng.pdf

Gleick, P. (2003). Global freshwater resources: Softpath solutions for the 21st century. Science, 302(5650), 1524-1528. https://doi.org/10.1126/ science. 1089967

Gonzalez, A., Donnelly, A., Jones, M., Klostermann, J., Groot, A., \& Breil, M. (2011). Community of practice approach to developing urban sustainability indicators. Journal of Environmental Assessment Policy and Management, 13(4), 591-617. https://doi.org/ 10.1142/S1464333211004024

Hoekstra, A., Buurman, J., \& Van Ginkel, K. (2018). Urban water security: A review. Environmental Research Letters, 13(5), Article 053002. https://doi.org/10.1088/ 1748-9326/aaba52

Isandla Institute. (2020). Backyarding: An important urban housing solution. https://www.isandla.org.za/ en/projects/urban-land/item/download/ 178_4caf00dd46ba3b76fd8b3c45406a96c5

Leonard, R., Iftekhar, S., Green, M., \& Walton, A. (2019). Community perceptions of the implementation and adoption of WSUD approaches for stormwater management. In D. Sharma, A. Gardner, \& T. Begbie (Eds.), Approaches to water sensitive urban design: Potential, design, ecological health, urban greening, economics, policies, and community perceptions (pp. 499-522). Woodhead Publishing.

Mguni, P., \& Carden, K. (2020, December). Pathways to water resilient South African cities-Mapping urban water management governance processes [Online paper presentation]. Water Institute of Southern Africa (WISA) 2020 Conference.

Otto, F., Wolski, P., Lehner, F., Tebaldi, C., Van Oldenborgh, G., Hogesteeger, S., Singh, R., Holden, P., Fučkar, N., Odoulami, R., \& New, M. (2018). Anthropogenic influence on the drivers of the Western Cape drought 2015-2017. Environmental Research Letters, 13(12), Article 124010. https://doi.org/ 10.1088/1748-9326/aae9f9
Pahl-Wostl, C., Vorosmarty, C., Bhaduri, A., Bogardi, J., Rockstrom, J., \& Alcamo, J. (2013). Towards a sustainable water future: Shaping the next decade of global water research. Environmental Sustainability, 5, 708-714.

Shackleton, C., Blair, A., De Lacy, P., Kaoma, H., Mugwagwa, N., Dalu, M., \& Walton, W. (2018). How important is green infrastructure in small and medium-sized towns? Lessons from South Africa. Landscape and Urban Planning, 180, 273-281. https://doi.org/10.1016/J.LANDURBPLAN.2016.12. 007

Tjandraatmadja, G. (2019). The role of policy and regulation in water sensitive urban design implementation. In A. Sharma, T. Gardner, \& D. Begbie (Eds.), Approaches to water sensitive urban design: Potential, design, ecological health, urban greening, economics, policies, and community perceptions (pp. 87-117). Woodhead Publishing. https://www. sciencedirect.com/science/article/pii/B9780128128 435000058

Truffer, B., Störmer, E., Maurer, M., \& Ruef, A. (2010). Local strategic planning processes and sustainability transitions in infrastructure sectors. Environmental Policy and Governance, 20(4), 258-269. https://doi. org/10.1002/eet.550

Walker, W. (2000). Entrapment in large technology systems: Institutional commitment and power relations. Research Policy, 29(7/8), 833-846. https://doi.org/10.1016/s0048-7333(00)00108-6

Wenger, E. (1998). Communities of practice: Learning, meaning and identity. Cambridge University Press.

Wolski, P., Conradie, S., Jack, C., \& Tadross, M. (2020). Spatio-temporal patterns of rainfall trends and the 2015-2017 drought over the winter rainfall region of South Africa. International Journal of Climatology, 41(S1), E1303-E1319. https://doi.org/10.1002/ joc. 6768

Wong, T. (2006). An overview of water sensitive urban design practices in Australia. Water Practice and Technology, 1(1). https://doi.org/10.2166/wpt.2006.018

Wong, T., Allen, R., Brown, R., Deletić, A., Gangadharan, L., Gernjak, W., Jakob, C., Johnstone, P., Reeder, M., Tapper, N., Vietz, G., \& Walsh, C. (2013). blueprint2013-Stormwater management in a water sensitive city. Cooperative Research Centre for Water Sensitive Cities.

Wong, T., \& Brown, R. (2009). The water sensitive city: Principles for practice. Water Science and Technology, 60(3), 673-682. https://doi.org/10.2166/wst. 2009.436

Wong, T., Rogers, B., \& Brown, R. (2020). Transforming cities through water-sensitive principles and practices. One Earth, 3(4), 436-447. https://doi.org/ 10.1016/j.oneear.2020.09.012 


\section{About the Authors}

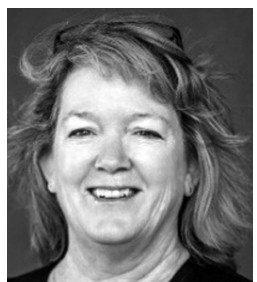

Kirsty Carden has over 30 years of experience working in academia, for government, and the private sector in South Africa. She is the interim director for UCT's interdisciplinary research institute, Future Water. Her research is focused largely on integrated approaches geared towards sustainable urban water management and water sensitive cities. She currently leads the multi-year Water Research Commission programme on the development and management of a national community of practice in water sensitive design.

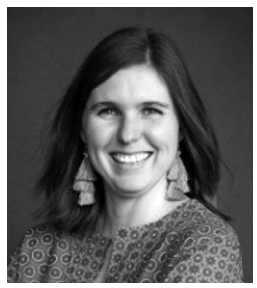

Jessica Fell is a PhD candidate in the Department of Civil Engineering at the University of Cape Town, with her thesis focusing on evaluating multi-functional blue-green infrastructure. She has almost three years of experience in the water sector working in academia and her research interests include water sensitive design and urban water services provision in South Africa. 